\title{
A gene pleiotropically controlling developmental and circadian periods in the melon fly, Bactrocera cucurbitae (Diptera: Tephritidae)
}

\author{
TORU SHIMIZU* $\uparrow$, TAKAHISA MIYATAKE $\uparrow$, YASUHIKO WATARI $\ddagger \&$ TETSUO ARAI $\ddagger$ \\ †Okinawa Prefectural Agricultural Experiment Station, 4-222 Sakiyama-cho, Naha 903, Japan and $\ddagger$ Laboratory of \\ Biotechnology, Ashiya University, 13-22 Rokurokuso-cho, Ashiya 659, Japan
}

\begin{abstract}
A gene causing an $8 \mathrm{~h}$ variation in the period of circadian rhythm in the adult locomotor activity was found in the melon fly Bactrocera cucurbitae by artificial selection for development time from egg to adult eclosion at $25 \pm 2^{\circ} \mathrm{C}$. The periods of free-running rhythm (mean $\pm \mathrm{SD}$ ) in constant darkness were $22.6 \pm 0.6$ and $22.5 \pm 0.4 \mathrm{~h}$, respectively, in two replicate lines selected for short development time, and $30.9 \pm 0.9$ and $26.5 \pm 3.6 \mathrm{~h}$, respectively, in two replicate lines selected for long development time. Thus, the development time and the period of circadian clock were correlated. The period locus was autosomal.
\end{abstract}

Keywords: artificial selection, Bactrocera cucurbitae, circadian rhythm, development time, free-running period, genetic correlation.

\section{Introduction}

Mutants affecting the period length of biological clocks have been found in several organisms, e.g. Drosophila (Konopka \& Benzer, 1971), Chlamydomonas (Bruce, 1972), Neurospora (Feldman \& Hoyle, 1973), hamster (Ralph \& Menaker, 1988), mouse (Vitaterna et al., 1994), cyanobacteria (Kondo et al., 1994) and Arabidopsis (Millar et al., 1995). These mutants may give clues towards the understanding of the mechanism of biological clocks.

In Drosophila melanogaster, several mutants influencing circadian clocks have been isolated (Hall, 1995). In the most studied per mutants, the rates of several processes, i.e. the circadian rhythms controlling adult eclosion (Konopka \& Benzer, 1971) and locomotor activity (Konopka \& Benzer, 1971), shortterm fluctuations in the pulse frequency in males' courtship song (Kyriacou \& Hall, 1980) and development time (Kyriacou et al., 1990) are altered by mutation in the per locus. These results suggested that the per locus controls the rate of some basic physiological process.

\footnotetext{
*Correspondence and present address: Laboratory of Natural Enemy Breeding, Department of Insect Genetics and Breeding, National Institute of Sericultural and Entomological Science, Tsukuba 305, Japan. E-mail: shim@nises.affrc.go.jp
}

Reppert et al. (1994) cloned per homologues in the moths Antheraea pernyi, Hyalophora cecropia and Manduca sexta, and in a cockroach, Periplaneta americana. Moreover, Levine et al. (1995) have demonstrated that the $A$. pernyi per homologue showed clock functions in transgenic $D$. melanogaster. These results suggest that per may be ubiquitous in Insecta.

Clock mutants, like in the Drosophila per, are expected to be found in other insects, but this has not yet happened. In this study we present evidence for a gene influencing the circadian period in Bactrocera cucurbitae (Coguillett) (Diptera: Tephritidae), by selection for development time from egg to adult eclosion.

\section{Materials and methods}

\section{Original stock and lines}

Miyatake (1995) selected for short (S line) and long (L line) development time from a mass-reared stock of B. cucurbitae maintained in the Okinawa Prefectural Fruit Fly Eradication Project Office, Okinawa, Japan (Nakamori et al., 1992). A mass-reared stock was established from 19281 individuals collected in Okinawa Island in 1985 (Kakinohana, 1996). S and L lines were started from the 41 st generation of the 
mass-reared stock. Each selection regime included two replicates, which were designated as S1 and S2 (short lines) or L1 and L2 (long lines), respectively. Larvae and adults were reared on artificial diets (see Nakamori \& Kakinohana, 1980; Nakamori et al., $1992)$ at $25 \pm 2{ }^{\circ} \mathrm{C}$ under $14 \mathrm{~h} \mathrm{L:} 10 \mathrm{~h} \mathrm{D}(14 \mathrm{~h}$ light: $10 \mathrm{~h}$ dark) photoperiod. A total of about 1600 eggs were seeded on the larval diet to initiate each generation of each line. As survival rates during the egg and larval stages varied among generations and lines, 168-1036 adults were obtained in each generation of each line. The sex ratios were always close to 0.5 . The first-emerged 50 males and 50 females were selected in every generation in the $\mathrm{S}$ lines and the last-emerged 50 males and 50 females in the $\mathrm{L}$ lines. After 28 generations of the $\mathrm{S}$ lines and 22 generations of the $\mathrm{L}$ lines, selection was relaxed. For further details of the selection procedure see Miyatake (1995). We used the 21st and 16th generations after the cessation of selection in the $\mathrm{S}$ and $\mathrm{L}$ lines, respectively, for studying circadian rhythms, and the 85-90th generations of the mass-reared stock served as controls. The means of development time from egg seeding to adult eclosion were $19.9 \pm 1.4$, $16.9 \pm 1.0,16.7 \pm 0.8,25.5 \pm 2.7$ and $24.6 \pm 2.3$ days (mean $\pm \mathrm{SD}$ ) at $25 \pm 2^{\circ} \mathrm{C}$ in the recent generations of the mass-reared stock, S1, S2, L1 and L2 lines, respectively (T. Miyatake, unpubl. obs.).

\section{Monitoring and parameters of the circadian rhythm}

Adults were kept singly in containers and provided with water and sugar (Fig. 1). Their locomotor activities were monitored by interruptions of an infrared beam and a photoelectric switch (OMRON, Tokyo). Signals of interruptions were sent to a computer (NEC, Tokyo) and the numbers recorded during every 6-min interval.

The free-running period was computed by the least-square spectrum (Chiba \& Takahashi, 1991) from free-running data for 2 weeks in D:D (continuous darkness) after a week of entrainment to $14 \mathrm{~h} \mathrm{L:10} \mathrm{h} \mathrm{D.} \mathrm{The} \mathrm{adult} \mathrm{age} \mathrm{at} \mathrm{the} \mathrm{transfer} \mathrm{from}$ $14 \mathrm{~h} \mathrm{~L}: 10 \mathrm{~h} \mathrm{D}$ to $\mathrm{D}: \mathrm{D}$ varied from 1 to 5 weeks.

A total of 239 out of 352 flies examined showed free-running rhythms. The remaining 113 flies died or did not show free-running rhythms clearly enough for calculating the periods.

\section{Crossing experiments}

We examined the first $\left(F_{1}\right)$ and the second $\left(F_{2}\right)$ generations after crossing between the $\mathrm{S}$ and $\mathrm{L}$ lines. We used the L1 line, which had a longer period of free-running than the L2 line, and S1 which had a similar free-running period to $\mathrm{S} 2$ in crossing experiments (see Results).

The free-running rhythms were determined also in the reciprocal crosses $\mathrm{S} \times \mathrm{L}$ (female $\times$ male) and $\mathrm{L} \times \mathrm{S}$. In the $\mathrm{F}_{2}$ generation, $\mathrm{S} \times \mathrm{L}$ and $\mathrm{L} \times \mathrm{S}$ flies were inbred and designated as $\mathrm{SL} \times \mathrm{SL}$ and $\mathrm{LS} \times \mathrm{LS}$. More than 50 pairs were used in each cross.

We examined the free-running periods of individuals with different development times in the $F_{2}$ generation in which the development time varied from 18 to 27 days $(21.2 \pm 2.0$ days, mean $\pm S D$, $n=2705$ ). Six females and six males with a development time of 20 days and an equivalent group with 24 days were tested in the crosses $\mathrm{SL} \times \mathrm{SL}$ and $\mathrm{LS} \times \mathrm{LS}$.

\section{Results}

Typical entrained and free-running rhythms of selected lines are presented in Fig. 2. Under $14 \mathrm{~h}$ $\mathrm{L}: 10 \mathrm{~h} \mathrm{D}$, most adults moved during the light period rather than the dark, but there was no sharp peak of

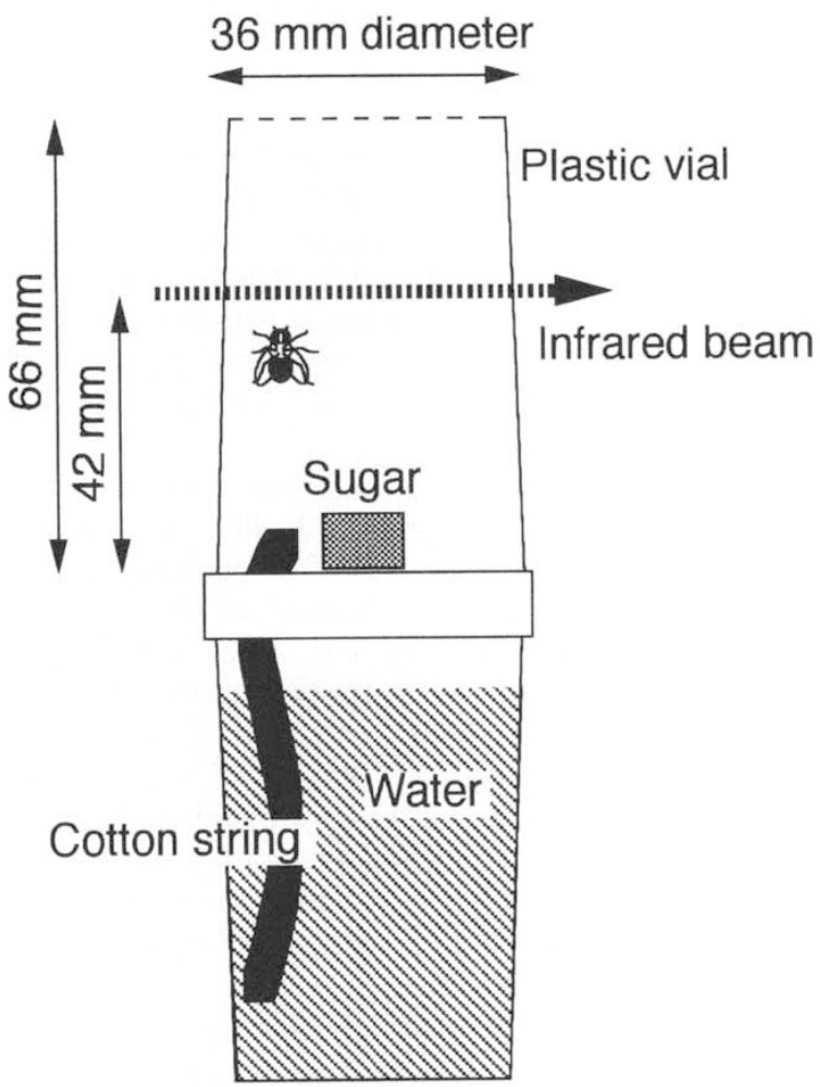

Fig. 1 The vial for recording locomotor activity in Bactrocera cucurbitae. Sugar was put in a plastic cup. 


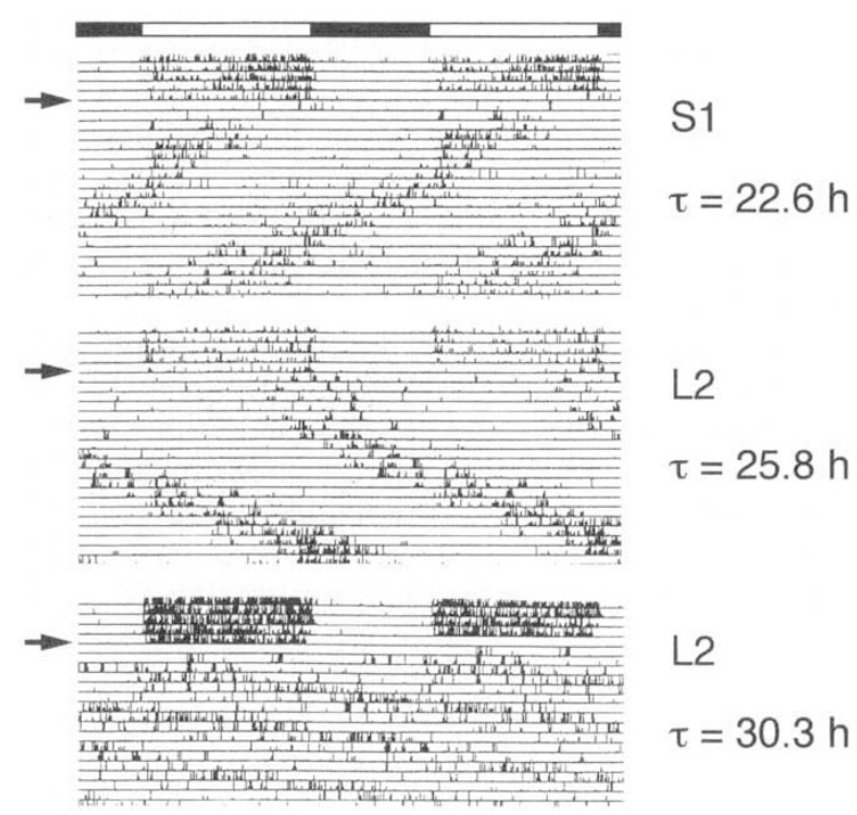

Fig. 2 Typical locomotor activity rhythms in the Bactrocera cucurbitae lines selected for short (S1) and long (L2) development time at $25 \pm 2^{\circ} \mathrm{C}$. Actograms are doubleplotted. The period $(\tau)$ of free-running rhythm of each individual is given on the right. Open and closed bars represent photophase and scotophase, respectively. The arrow indicates a shift from $14 \mathrm{~h} \mathrm{~L}: 10 \mathrm{~h} \mathrm{D}$ to D:D.

activity, although the pattern of the rhythm varied to some extent among days and individuals. This pattern was common in all selected lines.

The period of free-running rhythm was not different between the sexes (two-way ANOVA, $\left.F_{1,125}=2.19, P=0.141\right)$. Therefore, the results with males and females were pooled in the following analyses.

The distributions of free-running periods in the tested strains are shown in Fig. 3. The mass-reared stock was highly variable in the free-running period. The period of free-running rhythm was shortened by selection for short development time, and lengthened by selection for long development time. The periods of $\mathrm{S} 1$ and $\mathrm{S} 2$ were both shorter than those of L1 and L2 ( $t$-tests, $P<0.001$ in all cases). The difference between $\mathrm{S} 1$ and $\mathrm{S} 2$ was not significant $\left(t_{30}=0.48, P=0.634\right)$, but it was significant between $\mathrm{L} 1$ and $\mathrm{L} 2\left(\mathrm{~L} 1>\mathrm{L} 2 ; t_{54}=5.59, P<0.001\right)$. We consider that the effect of selection for a long period had not reached a plateau.

The periods of free-running rhythms of crosses between the $\mathrm{S}$ and $\mathrm{L}$ lines are shown in Fig. 4. Freerunning rhythms of periods longer than $28 \mathrm{~h}$ were not observed in $F_{1}$ hybrids, but were clearly expressed in some $F_{2}$ flies. This suggests a major gene controlling the free-running rhythm and the segregation of the alleles in the $F_{2}$. Because the mean period of free-running rhythm in the $F_{1}$ was closer to that in the $\mathrm{S}$ lines, the shorter period was partially dominant. However, the segregation was not complete. The period of free-running rhythm was more variable in the $F_{1}$ than in the parents and

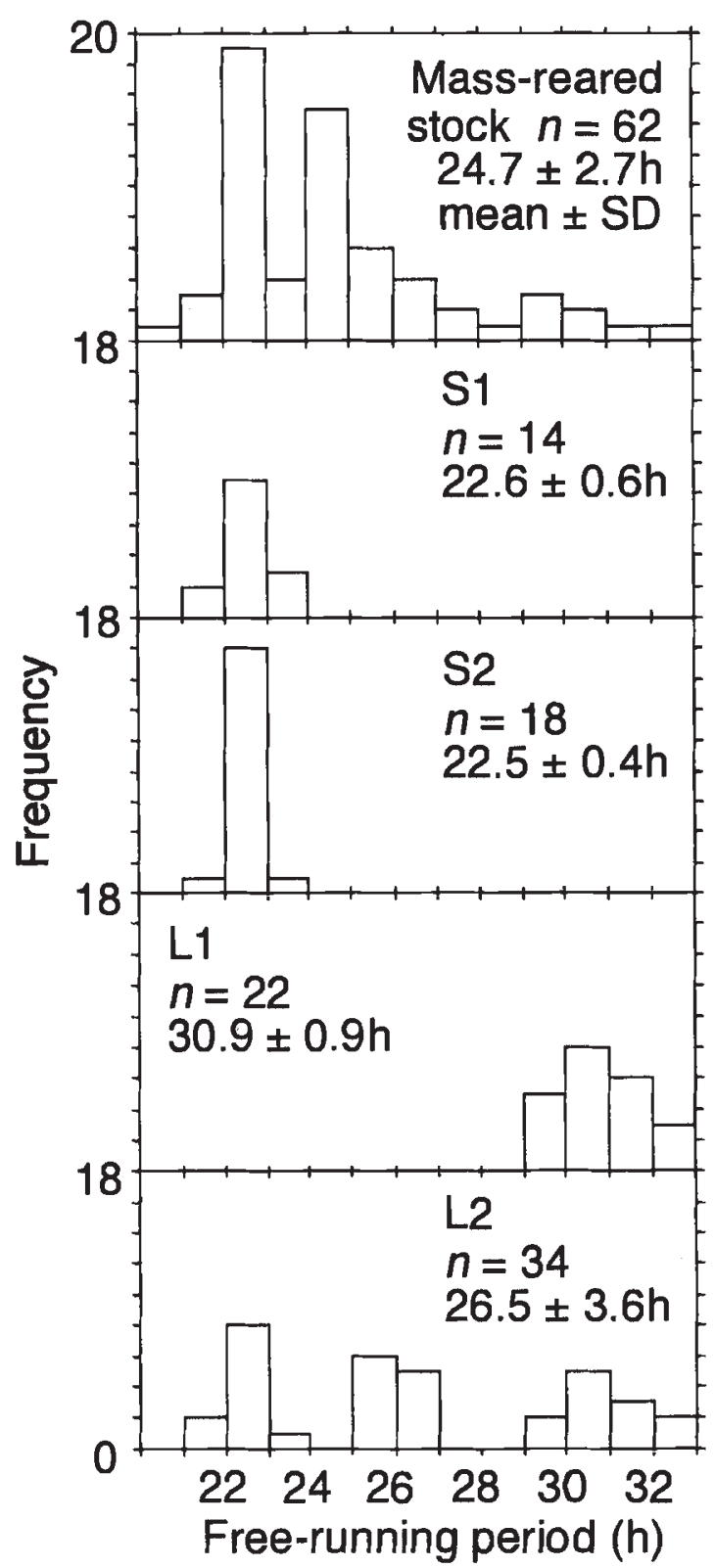

Fig. 3 Frequency distributions of the periods of freerunning rhythm in the mass-reared Bactrocera cucurbitae stock and the lines selected for short (S1 and S2) and long (L1 and L2) development time.

(c) The Genetical Society of Great Britain, Heredity, 79, 600-605. 
was distributed bimodally. There might also be other factors or minor genes contributing to the circadian function.

Higher dipterans have sex chromosomes $\mathrm{X}$ and $\mathrm{Y}$, with the male heterogametic $X Y$ and the female homogametic XX. There was no difference in the males between the reciprocal crosses $\left(t_{19}=0.51\right.$, $P=0.616$ ). Therefore, the major gene was not on the sex chromosome.

In the $F_{2}$, in which the period alleles segregated, the free-running rhythm was significantly shorter in individuals with a short development time of 20 days $(\tau=23.9 \pm 2.6 \mathrm{~h}$, mean $\pm \mathrm{SD})$, than in those with a long one of 24 days $(\tau=27.3 \pm 2.8 \mathrm{~h})$ when $\mathrm{SL} \times \mathrm{SL}$ and LS $\times$ LS were pooled $\left(t_{30}=3.47, P=0.002\right)$. Even within each type of cross, there was a similar

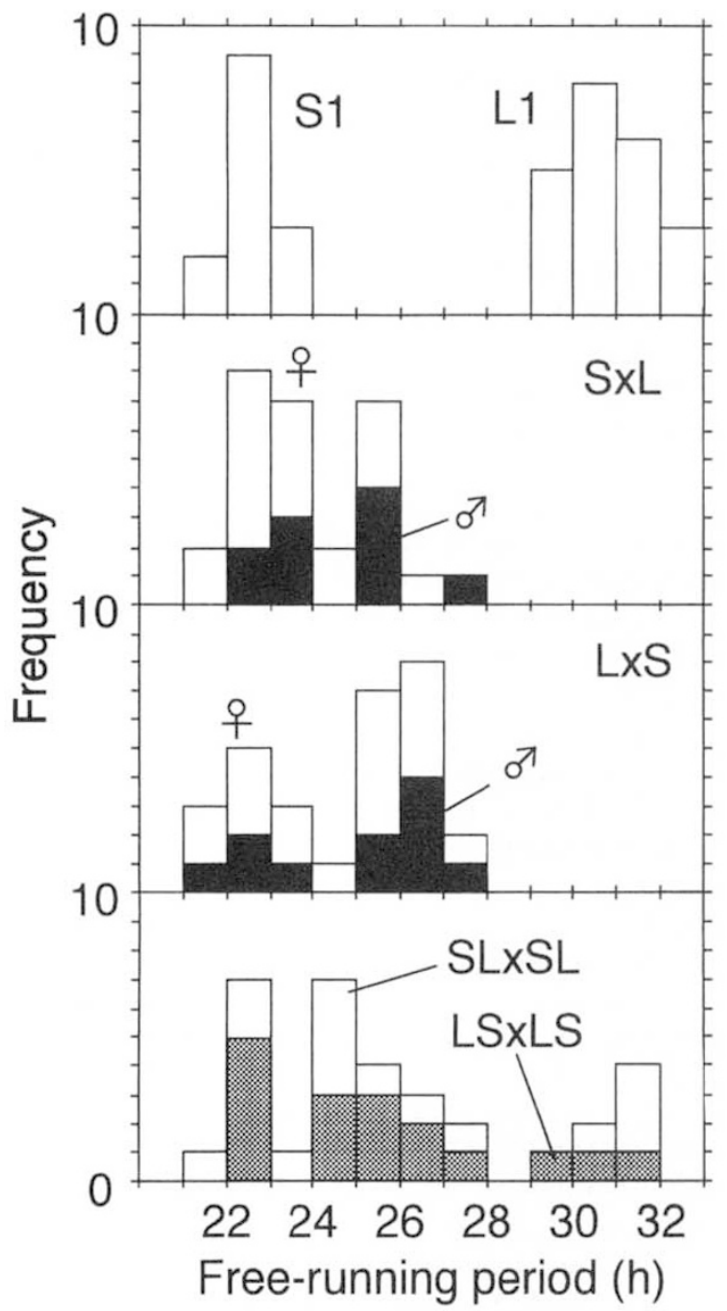

Fig. 4 Periods of free-running rhythm in the selected Bactrocera cucurbitae strains and their hybrids. Males (closed bars) and females (open bars) are shown separately in $\mathrm{F}_{1}$ hybrids. tendency $\left(t_{13}=1.89, \quad P=0.082\right.$ and $t_{15}=3.08$, $P=0.008$ in SL $\times$ SL and LS $\times$ LS, respectively).

\section{Discussion}

We found a gene altering the circadian period by about $8 \mathrm{~h}$ in the melon fly $B$. cucurbitae. The gene effect was comparable to that of the Drosophila per alleles (Konopka \& Benzer, 1971) and the Neurospora frq alleles (Gardner \& Feldman, 1980). It is interesting that this gene has been isolated by selection for development time which does not immediately control the circadian rhythm.

In clock mutants of cyanobacteria, the circadian period varied from 16 to $60 \mathrm{~h}$, but the development time (doubling time) was not so variable (Kondo et al., 1994). In Drosophila, on the other hand, the development time from hatching to adult eclosion was $10-15 \mathrm{~h}$ shorter in mutants with a short $(19 \mathrm{~h})$ circadian period than in those with a long $(29 \mathrm{~h})$ one (Kyriacou et al., 1990). In Neurospora, frq mutants did not alter the development time, but a prd mutant (formerly called frq-5 but in a different linkage group from that of frq) lowered the rate of the circadian clock by $4 \mathrm{~h}$ and delayed development by 60 per cent (Feldman \& Atkinson, 1978). Thus, the pleiotropic effect on the circadian clock and developmental rate varies among organisms and loci.

Our detection of a period gene in Bactrocera was probably because of its relatively large pleiotropic effect on the circadian rhythm and development time. $\mathrm{F}_{2}$ hybrids differing 4 days in development time were significantly different in their circadian periods. However, the developmental difference was not caused by the gene for period alone. The development time was similarly lengthened in the two replicate L lines (L1 and L2), but the circadian period was not (Fig. 3). This may result from the existence of genes affecting development time but not the circadian clock.

In Bactrocera, the pleiotropic effect of the period gene on the circadian rhythm and development may suggest that this gene controls the rate(s) of some basic physiological process(es). In Caenorhabditis elegans, mutants which pleiotropically lengthen embryonic cell cycles, development, lifespan and period of adult rhythmic behaviours, e.g. swimming, pharyngeal pumping and defaecation, have been found, and the genes were inferred to control the metabolic rate (Wong et al., 1995; Lakowski \& Hekimi, 1996).

There may be another reason for the pleiotropic effect of the period gene; for example, when the period of the circadian clock is longer than $24 \mathrm{~h}$, as 
in the $\mathbf{L}$ line, the norm of development for a day may not be fulfilled every day. This may result in a long development time.

In $B$. cucurbitae, the mating time was also different between the $\mathrm{S}$ and $\mathrm{L}$ lines, and the $\mathrm{S}$ line mated $5-7 \mathrm{~h}$ earlier than the $\mathrm{L}$ line (Miyatake, 1997). Generally, the circadian time is correlated with the circadian period, and the long circadian period causes late circadian events (Pittendrigh, 1981). If locomotion and the time of mating are controlled by the same clock, as was the case in Pectinophora gossypiella, in which the times of hatching, adult eclosion and oviposition were signalled by the same circadian clock (Pittendrigh \& Minis, 1971), the late time of mating of a fly with long circadian periods may be explained by the general feature of the circadian clock. The period gene may also control other behavioural and physiological events, such as hatching and adult eclosion.

The mass-reared stock that provided the starting gene pool for our selection experiments was variable with respect to this gene (Fig. 3). Why has such variability been preserved in the mass-reared stock? It should be noted that this stock has been maintained for more than 41 generations before selection for development time. Two possibilities can be suggested for the high variability. First, in the wild population of B. cucurbitae, one of the two alleles of the period locus was absent or its frequency was very low, and it appeared by mutation and/or its frequency was enhanced in the mass-reared stock owing to the method of maintaining it (see below). Secondly, the wild population of $B$. cucurbitae was originally highly polymorphic (variable) at the period locus and frequencies of the two alleles were near 50 per cent, as in the current mass-reared stock.

In the mass-reared stock, individuals with short and long development time were used as parents in every generation (Nakamori et al., 1992). Although the selection in the mass-reared stock may be much weaker than the stringent selection imposed by Miyatake (1995), it is possible that the culturing procedure of the stock increased and maintained variation in the development time and the circadian period.

As a consequence of spreading risks of food deficiency in the field, variability in the development time of the wild melon fly may be maintained by natural selection. This would cause high variability in the period locus. This hypothesis cannot be tested in Japan because the wild populations have been eradicated (Kuba et al., 1996). It would be interesting to investigate the genetic variability of develop- ment time and circadian period of wild melon flies in India and south-east Asia.

The period gene locus is not on the sex chromosome as is the Drosophila per locus. The period genes in Drosophila and Bactrocera may be of different origins. Whether period genes are universal in insects or not is an intriguing evolutionary problem. To detect such genes, selection for development time, which can be selected easily, may be a useful method, as in B. cucurbitae.

\section{Acknowledgements}

We thank Dr S. Masaki of Hirosaki University and Dr A. A. Hoffmann of La Trobe University, Australia for their suggested revisions to the manuscript.

\section{References}

BRUCE, V. G. 1972. Mutants of the biological clock in Chlamydomonas reinhardi. Genetics, 70, 537-548.

Chiba, y. AND takahashi, к. 1991. Chronobiology Handbook. Asakura shoten, Tokyo (in Japanese).

FELDMAN, J. F. AND ATKINSON, C. A. 1978. Genetic and physiological characteristics of a slow-growing circadian clock mutant of Neurospora crassa. Genetics, 88, $255-265$.

FELDMAN, J. F. AND HOYLE, M. N. 1973. Isolation of circadian clock mutants of Neurospora crassa. Genetics, $\mathbf{7 5}$, 605-613.

GARDNER, G. F. AND FELDMAN, J. F. 1980. The frq locus in Neurospora crassa: a key element in circadian clock organization. Genetics, 96, 877-886.

HALL, J. C. 1995. Tripping along the trial to the molecular mechanisms of biological clocks. Trends Neurosci., 18, 203-240.

KaKINOHANA, H. 1996. Studies on the mass production of the melon flies, Bactrocera cucurbitae Coquillett. Bull. Okinawa Agric. Exp. Stn, 16, 1-102 (in Japanese with English summary).

KONDO, T., TSINOREMAS, N. F., GOLDEN, S. S., JOHNSON, C. H., KUTSUNA, S. AND ISHIURA, M. 1994. Circadian clock mutants of cyanobacteria. Science, 266, 1233-1236.

KONOPKA, R. J. AND BENZER, s. 1971. Clock mutants of Drosophila melanogaster. Proc. Natl. Acad. Sci. U.S.A., 68, 2112-2116.

KUBA, H., KOHAMA, T., KakinOHANa, H., YAMAGISH, M., KINJO, K., SOKEI, Y. ET AL. 1996. The successful eradication programs of the melon fly in Okinawa. In: McPheron, B. A. and Steck, G. J. (eds) Fruit Fly Pests, $A$ World Assessment of Their Biology and Management, pp. 543-550. St. Lucie Press, Delray Beach, FL.

KYRIACOU, C. P. AND HALL, J. c. 1980 . Circadian rhythm mutations in Drosophila affect short-term fluctuations in the male's courtship song. Proc. Natl. Acad. Sci. U.S.A., 77, 6929-6933. 
KYRIACOU, C. P., OLDROYD, M., WOOD, J., SHARP, M. AND HILl, M. 1990. Clock mutations alter developmental timing in Drosophila. Heredity, 64, 395-401.

LAKOWSK1, B. AND HEKIMl, S. 1996. Determination of lifespan in Caenorhabditis elegans by four clock genes. Science, 272, 1010-1013.

LEVINE, J. D., SAUMAN, I., IMBALZANO, M., REPPERT, S. M. AND JACKSON, F. R. 1995. Period protein from the giant silkmoth Antheraea pernyi functions as a circadian clock element in Drosophila melanogaster. Neuron, 15, 147-157.

MILlaR, A. J., CARRÉ, l. A., STRAYER, C. A., CHUA, N. H. AND KAY, S. A. 1995. Circadian clock mutants in Arabidopsis identified by luciferase imaging. Science, 267, 1161-1163.

MIYATAKE, T. 1995. Two-way artificial selection for developmental period in Bactrocera cucurbitae (Diptera: Tephritidae). Ann. Entomol. Soc, Am., 88, 848-855.

MiyATAKE, T. 1997. Correlated responses to selection for developmental period in Bactrocera cucurbitae (Diptera: Tephritidae): time at mating and daily activity rhythms. Behav. Genet., 27, 489-498.

NAKAMORI, H. AND KAKINOHANA, H. 1980. Mass-production of the melon fly, Dacus cucurbitae Coquillett in Okinawa, Japan. Rev. Plant Prot. Res., 13, 37-53.

NAKAMORI, H., KAKINOHANA, H. AND YAMAGISHI, M. 1992. Automated mass production system for fruit flies based on the melon fly, Dacus cucurbitae Coquillett (Diptera: Tephritidae). In: Anderson, T. E. and Leppla, N. C. (eds) Advances in Insect Rearing for Research and Pest Management, pp. 441-454. WestView Press, Oxford.

PITTENDRIGH, C. S. 1981. Circadian systems: Entrainment. In: Aschoff, J. (ed.) Handbook of Behavioral Neurobiology, vol. 4, Biological Rhythms, pp. 95-124. Plenum Press, New York.

PITTENDRIGH, C. S. AND MINIS, D. H. 1971. The photoperiodic time measurement in Pectinophora gossypiella and its relation to the circadian system in that species. In: Menaker, M. (ed.) Biochronometry, pp. 212-250. National Academy of Sciences, Washington, DC.

RALPH, M. R. AND MENAKER, M. 1988. A mutation of the circadian system in golden hamsters. Science, 241, $1225-1227$.

REPPERT, S. M., TSAl, T., ROCA, A. L. AND SAUMAN, 1. 1994. Cloning of a structural and functional homolog of the circadian clock gene period from the giant silkmoth Antheraea pernyi. Neuron, 13, 1167-1176.

Vitaterna, M. H., KING, D. P., CHANG, A. M., KORNHAUSER, J. M., LOWREY, P. L., McDonALD, J. D. ET AL. 1994. Mutagenesis and mapping of a mouse gene, clock, essential for circadian behavior. Science, 264, 719-725.

wONG, A., BOUTIS, P. AND HEKIMI, S. 1995. Mutations in the clk-1 gene of Caenorhabditis elegans affect developmental and behavioral timing. Genetics, 139, 1247-1259. 